\title{
Etiology of Congenital Diaphragmatic Hernia: The Retinoid Hypothesis
}

\author{
JOHN J. GREER, RANDAL P. BABIUK, BERNARD THEBAUD \\ Department of Physiology [J.J.G., R.P.B.], Department of Pediatrics [B.T.], Perinatal Research Centre, \\ Vascular Biology Research Group, University of Alberta, Edmonton, Canada
}

\begin{tabular}{|c|c|}
\hline \multicolumn{2}{|c|}{ ABSTRACT } \\
\hline $\begin{array}{l}\text { Congenital diaphragmatic hernia }(\mathrm{CDH}) \text { is a major life- } \\
\text { threatening cause of respiratory failure in the newborn. Although } \\
\text { significant efforts have been undertaken to unravel the patho- } \\
\text { physiology of } \mathrm{CDH} \text {, our current understanding of the etiology } \\
\text { remains spare. Here we outline recent evidence suggesting that } \\
\text { abnormalities linked with the retinoid signaling pathway early in } \\
\text { gestation may contribute to the etiology of CDH. These studies } \\
\text { include } 1 \text { ) the effect of altering the retinoid system in vitamin A } \\
\text { deficient and transgenic animals; } 2 \text { ) disruption of the retinoid } \\
\text { system in teratogen-induced CDH in rodents, 3) the effect of } \\
\text { co-administration of retinoids in nitrofen-induced CDH on lung } \\
\text { and diaphragm development, and 4) clinical evidence suggesting } \\
\text { decreased markers of vitamin A status in human CDH. Given the } \\
\text { substantial mortality and morbidity associated with this serious } \\
\text { developmental anomaly, advancements in this area will be crit- } \\
\text { ical. We feel that there is now sufficient circumstantial and direct }\end{array}$ & $\begin{array}{l}\text { experimental evidence to warrant further testing of the retinoid- } \\
\text { CDH etiology hypothesis, including examination of retinoid- } \\
\text { regulated target genes that could be candidates for involvement } \\
\text { in CDH. (Pediatr Res 53: 726-730, 2003) } \\
\qquad \text { Abbreviations } \\
\text { BPCA, Biphenyl carboxylic acid } \\
\text { CDH, congenital diaphragmatic hernia } \\
\text { CRABP1, cellular retinoic acid binding protein } 1 \\
\text { ECMO, extracorporeal membrane oxygenation } \\
\text { IEF, isoelectric focusing } \\
\text { PPF, pleuroperitoneal fold } \\
\text { RALDH-2, retinal dehydrogenase } \\
\text { RAR, retinoic acid receptor } \\
\text { RARE, retinoic acid response element }\end{array}$ \\
\hline
\end{tabular}

Severe respiratory failure in the newborn remains a main cause of neonatal death (1). Among the causes of severe respiratory failure in the newborn, congenital diaphragmatic hernia $(\mathrm{CDH})$ remains the most life threatening $(2,3)$. Despite improvements in survival, the mortality rate is still high in many centers, and morbidity remains significant, with chronic oxygen dependence, gastroesophageal reflux, poor growth and developmental delay, and prolonged postoperative hospitalization of affected neonates (4). A major factor limiting survival in $\mathrm{CDH}$ is the degree of lung hypoplasia. Although tremendous efforts have been undertaken to unravel the pathophysiology of $\mathrm{CDH}$, our current understanding of the pathogenesis and etiology remains spare. In this perspective, we review evidence

Received November 21, 2002; Accepted: January 16, 2003.

Correspondence: Dr. John J. Greer, 513 HMRC, University of Alberta, Department of Physiology, Perinatal Research Centre, Edmonton, AB, Canada T6G 2S2; e-mail: john.greer@ualberta.ca

This work was funded by grants from the Canadian Institutes of Health Research (CIHR) and March of Dimes. JJG is a Senior Scholar of the Alberta Heritage Foundation for Medical Research (AHFMR). BT was a Postdoctoral Fellow of the Alberta Heritage Foundation for Medical Research (AHFMR) and CIHR and sponsored by a grant from the French Ministry for Foreign Affairs, the Fondation pour la Recherche Médicale and the Société Française de Médecine Périnatale. RB is the recipient of an Alberta Lung Association Studentship.

DOI: 10.1203/01.PDR.0000062660.12769.E6 linking abnormalities of the retinoid system and the occurrence of CDH. From the outset, it should be emphasized that a direct linkage between the etiology of $\mathrm{CDH}$ and retinoids has not been established. However, we summarize data from a variety of studies that provide a firm foundation for establishing the hypothesis that abnormalities within the retinoid signaling pathway during the early gestation contribute to the etiology of $\mathrm{CDH}$.

\section{CONGENITAL DIAPHRAGMATIC HERNIA: THE CLINICAL DILEMMA}

CDH occurs in 1/2500 live births (5). This malformation was first described in 1848 by Bochdalek, and for many years was thought to be a simple hole in the diaphragm, potentially curable by surgical closure of the defect after birth. However, unlike other causes of respiratory failure in the newborn, infants with $\mathrm{CDH}$ do not respond to our modern therapeutic armamentarium, including exogenous surfactant, high frequency oscillatory ventilation and inhaled nitric oxide (6). When conventional therapy fails, extra-corporeal membrane oxygenation (ECMO), a highly invasive, labor-intensive and expensive technique $(>\$ 250,000$ per patient (7)) with significant risks is applied in some centers. ECMO bypasses the lung 
for a few days allowing pulmonary vascular resistance to lower, but it does not overcome the basic problem of this devastating malformation: lung hypoplasia. As a result, infants with severe hypoplastic lungs die or suffer significant morbidity. The antenatal diagnosis of $\mathrm{CDH}$ has been possible for nearly two decades. However, apart from the coexistence of any congenital defect or chromosomal abnormality, no single antenatal feature has been shown to accurately predict outcome in fetuses with $\mathrm{CDH}$ (8). Therefore, the multidisciplinary perinatal staff faces a dilemma, both ante- and postnatally. Antenatally, in case of in utero diagnosis of isolated $\mathrm{CDH}$, it is difficult to accurately advise the parents on the prognosis; postnatally, in cases of severe respiratory failure, it is difficult, in the absence of reliable prognostic indicators, to decide how aggressive and sustained life support should be. Consequently, the ultimate therapeutic goal would be to prevent the diaphragmatic defect and/or to promote lung growth before birth to increase survival and decrease the morbidity of this malformation. This however requires a better understanding of the mechanisms controlling diaphragm formation and lung growth in $\mathrm{CDH}$.

\section{INSIGHTS INTO THE PATHOGENESIS OF CDH FROM ANIMAL MODELS}

The nitrofen model in rodents has been used widely to examine lung and muscle malformations associated with $\mathrm{CDH}$. The use of this animal model arose from routine toxicological studies demonstrating that, while nitrofen (2,4-dichlorophenyl-p-nitrophenyl ether) was relatively nontoxic to adult animals, administration between E8-E11 resulted in $~ 50 \%$ of the fetuses developing diaphragm malformations that were remarkably similar to those seen in infants with $\mathrm{CDH}(9-12)$. The similarities hold true with regard to the specific location and extent of diaphragmatic defects as well as the periodic occurrence of associated anomalies affecting cardiac, pulmonary and skeletal tissues. More recently, three additional compounds that cause diaphragmatic defects in rats have been characterized (13). Biphenyl carboxylic acid (BPCA), bisdiamine [N,N'-octamethylenebis (dichloroacetamide)] and SB210661, all induce diaphragmatic as well as cardiopulmonary, dermal and skeletal defects in the fetuses isolated from treated pregnant rats. BPCA is a breakdown product of a thromboxane- $\mathrm{A}_{2}$ receptor antagonist, bisdiamine is a spermatogenesis inhibitor and SB-210661 is a benzofuranyl urea derivative developed for inhibiting 5-lipoxygenase. The timing of administration of all of the $\mathrm{CDH}$-inducing teratogen is critical. Rodents are most susceptible between E9-11, a developmental window corresponding to gestational weeks $4-6$ in humans.

Animal models of $\mathrm{CDH}$ are beginning to provide insights into the pathogenesis, pathophysiology and etiology of $\mathrm{CDH}$ (reviewed in (14-16)). With regards to the pathogenesis, data from the nitrofen model of $\mathrm{CDH}$ refutes the long-standing hypothesis that a failure of pleuroperitoneal canal closure underlies the anomaly. Rather, defects can be traced to a much earlier stage of development, during the formation of the primordial diaphragm, the pleuroperitoneal fold (PPF) (17). Three-dimensional reconstructions of the PPF have demonstrated that the malformed areas are consistently located in the dorsolateral region (18) where $90 \%$ of the diaphragmatic defects occur in human. Examinations of the muscle precursor migration to the PPF and subsequent proliferation and differentiation did not reveal any obvious abnormalities (19). However, the underlying substratum of the PPF to which muscle precursors migrate to and subsequently proliferate and differentiate upon appeared abnormal. That data led to the hypothesis stating that the amuscular mesenchymal component of the PPF, likely derived from the somatopleure, is defective and does not provide a full foundation for the formation of diaphragmatic musculature. We tested the hypothesis using mice in which muscle precursors fail to migrate to peripheral muscle, including the diaphragm, due to homozygous mutation $(-/-)$ of the $c$-met gene (20). While the diaphragmatic musculature fails to form in the null-mutants, the underlying connective tissue that comprises the amuscular substratum forms fully, thus, offering the opportunity to clearly visualize the formation of the amuscular component of the diaphragm in normal and nitrofen-exposed animals. It was demonstrated that a defect characteristic of $\mathrm{CDH}$ could be induced in the amuscular membrane.

Lung hypoplasia and vascular remodeling in $\mathrm{CDH}$ results from the invasion of the abdominal contents into the thoracic cavity and the lack of efficient fetal breathing movements that are associated with defects in the diaphragm. Indeed, pulmonary hypoplasia and hypertension characteristic of $\mathrm{CDH}$ develop as a result of surgically induced diaphragmatic defects in the fetal sheep model $(14,21)$. However, there is evidence from the nitrofen model that there is some degree of abnormal lung development that occurs independent of those resulting secondarily to the diaphragm defects (22-25). Whether or not this is simply a reflection of the specific pathogenesis of the nitrofen model or indicative of what happens in $\mathrm{CDH}$ is not known. There could well be a common mechanism underlying the etiology of $\mathrm{CDH}$ that targets diaphragm and lung development in parallel. There is a more extreme hypothesis stating that the lung hypoplasia is the primary defect that in turn causes the diaphragm defect (26). Implicit in that hypothesis is the notion that diaphragm embryogenesis is regulated or influenced directly by the development of the adjacent lung tissue. Recently, FGF10 null-mutant mice that do not develop lung tissue have been used to address this issue (20). Specifically, it was tested whether or not lung tissue was necessary for 1 ) normal diaphragm formation and 2) diaphragm defects in animal model of $\mathrm{CDH}$. Two conclusions arose from the study. First, the diaphragm forms normally independent of lung development. Second, defects in the diaphragm in an animal model of $\mathrm{CDH}$ occur in the absence of lung tissue.

\section{RETINOIDS AND CDH: EXPERIMENTAL EVIDENCE}

Vitamin A deficiency studies. The first published evidence linking retinoids with $\mathrm{CDH}$ came from the examination of pups born to dams with Vitamin A deficient diets (27-30). Diaphragmatic hernias were present in $25 \%$ to $40 \%$ of the offspring of Vitamin A deficient dams, with the majority having right-sided defects. The rate of herniation was decreased when Vitamin A was introduced into the diet during mid-gestation. 
Retinoid receptor knock-out mice. The developing diaphragm strongly expresses proteins associated with the metabolism and binding of retinoids $(13,31)$. Studies of retinoid receptor double null-mutant mice, lacking both $\alpha$ and $\beta$ subtypes of retinoic acid receptors (RAR), have demonstrated that some offspring have diaphragmatic hernias similar to those observed with nitrofen exposure or $\mathrm{CDH}(32,33)$. Presumably, those are among the receptor subtypes involved in the development of the component of the primordial diaphragm, the PPF, affected in CDH. The role of retinoids in PPF formation is a primary focus of ongoing investigation.

Nitrofen-induced suppression of retinoid response element activation. Given the similarities between the defects induced by nitrofen and those observed in infants with $\mathrm{CDH}$, there is an interest in understanding the biochemical mechanisms of nitrofen's actions in hopes of gaining insights into the etiology of $\mathrm{CDH}$. Until recently, there was no substantial data demonstrating the mechanism by which nitrofen was inducing diaphragmatic defects. The data derived from the Vitamin A deficient diet and retinoid receptor null mutant studies provided the foundation for the hypothesis stating that nitrofen is acting to perturb the retinoid signaling pathway. This hypothesis was first tested using genetically engineered mice that had the lacZ reporter gene linked to a retinoic acid response element (RARE; Fig. 1). There was a pronounced suppression of RARE-lacZ expression by nitrofen in in vitro whole embryo

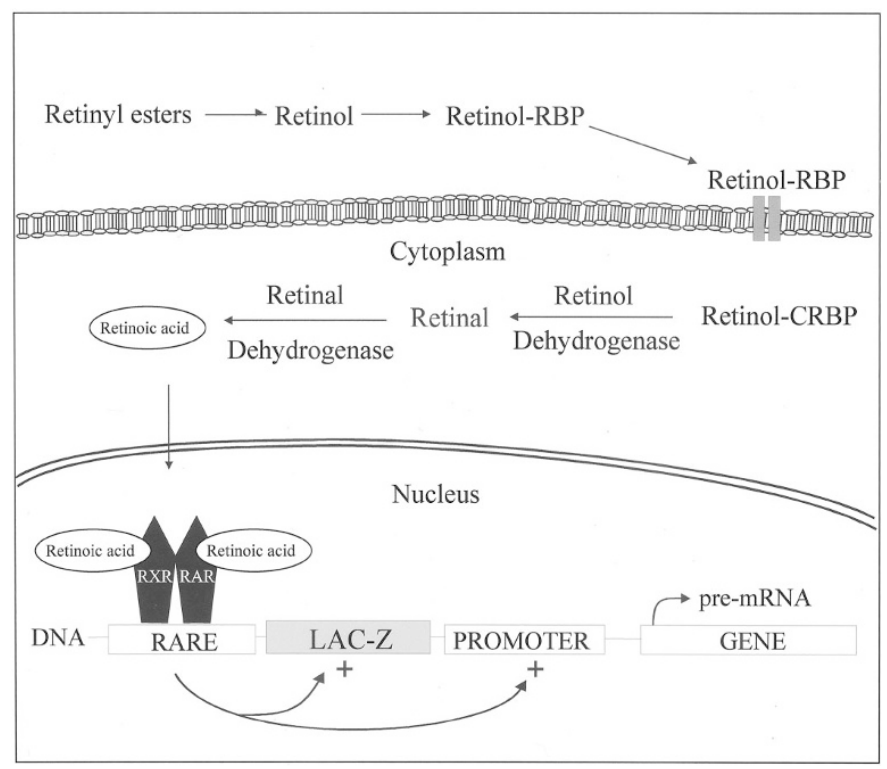

Figure 1. Simplified schematic of the retinoid signaling pathway. Retinol bound to retinol binding protein (RBP) is transferred from the liver via blood to target cells. Retinol-RBP complex binds to cell surface receptors and is internalized. Within the cytoplasm retinol is bound to cellular retinol binding proteins (CRBP). Retinol is converted to retinal by retinol dehydrogenase followed by a further dehydrogenation to retinoic acid by retinal dehydrogenase. Retinoic acid (all-trans RA and 9-cis-RA) binds to receptors (RAR and RXR families) that dimerize and regulate gene expression by binding to short DNA sequences in the vicinity of target genes. Mice that have a lac-Z reporter gene linked to a retinoid response element (RARE) were used to detect nitrofen-induced suppression of RARE activation. Subsequent studies demonstrated that the depression of RARE activation by nitrofen and other $\mathrm{CDH}$ inducing compounds could be explained by an inhibition of retinal dehydrogenase enzyme. culture and in in vivo mouse models (Fig. 2) (34). Further, the nitrofen-induced suppression in vitro was antagonized by supplemental administration of retinoic acid. Those experiments provided direct evidence linking a perturbation of the retinoid signaling pathway with an animal model of $\mathrm{CDH}$.

CDH-inducing teratogens inhibit retinal dehydrogenase. The studies demonstrating the suppression of retinoic acid regulated gene transcription by nitrofen generated two fundamental questions. First, is the effect limited to the actions of nitrofen? Second, what component of the retinoid signaling pathway is being affected upstream of the RARE? These issues were addressed in a subsequent study that tested the hypothesis that all four compounds that induce $\mathrm{CDH}$ were working through the common mechanism of inhibiting retinal dehydrogenase (RALDH-2) (13), the major retinoic acid-synthesizing enzyme that has recently been shown to play an important role during lung development (35). The immortalized oligodendrocyte cell line OLN93 was used as a source of retinal dehydrogenase to investigate the inhibitory effect of nitrofen, bisdiamine, BPCA and SB-210661. Cytosolic extracts were separated with nondenaturing isoelectric focusing (IEF) and tested for the ability to synthesize retinoic acid from all-trans retinal. The data derived from the study clearly demonstrated that all four CDH-inducing compounds inhibit RALDH-2 in a dose-dependent manner. Further, the most potent inhibitor of RALDH-2, bisdiamine, was also the most effective at inducing diaphragmatic defects in embryonic rats (13).

Co-administration of retinoids and nitrofen. The coadministration of large doses of Vitamin A (25,000 IU) and nitrofen can reduce the incidence of $\mathrm{CDH}$ by $\sim 15 \%$ to $30 \%$ and attenuate lung hypoplasia $(36,37)$. To counteract the actions of nitrofen administered on E8, Vitamin A must be delivered on multiple days to have any effect with the crucial window including days E10-11. The interpretation of these data, in light of the RALDH-2 studies, is that the large doses of Vitamin A provide a marked increase in the substrate for conversion to retinoic acid. This partially offsets the decreased activity of RALDH-2 toward the production of retinoic acid.

Why are certain tissues targeted in $\mathbf{C D H}$ ? In $\sim 60 \%$ to $65 \%$ of cases in infants with $\mathrm{CDH}$ there are no obvious associated anomalies other than the diaphragm defect $(38,39)$. In the rat nitrofen model of $\mathrm{CDH}$, the diaphragm defect is typically most prominent. Interestingly, during the time of susceptibility to nitrofen (E9-E11), there is a severe dip in retinol levels in the rat due to acute increases in retinol utilization (40). Thus, the embryo may be particularly susceptible to perturbations of retinoid levels or function during this period. The developing lung, which expresses RALDH-2 and relies on retinoidmediated signaling for proper development (35), is also compromised by nitrofen (Fig. 3) (22-25). Further, heart development is particularly susceptible, as cardiac anomalies are the most common associated defect in infants with $\mathrm{CDH}$ (38) and are observed in the rat model of nitrofen-induced CDH (4143). It is conceivable that the "safety margin" for retinoic acid mediated regulation of primordial diaphragm, lung and heart development is relatively low and thus more susceptible to perturbations compared with other tissues. 
Control

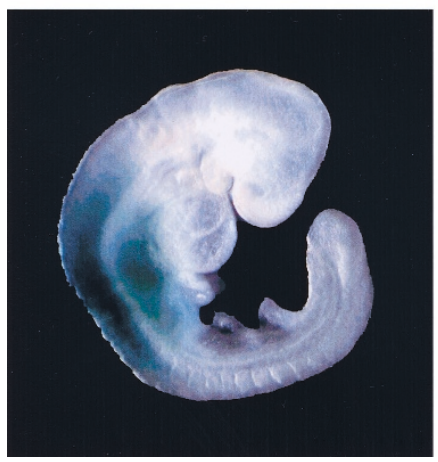

Nitrofen

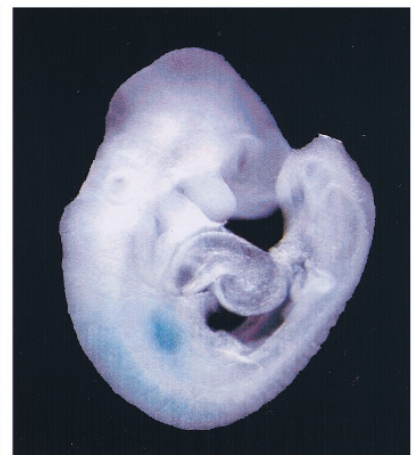

Nitrofen + RA

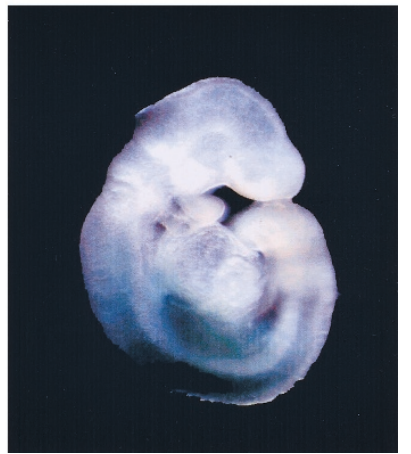

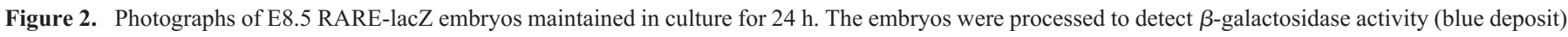

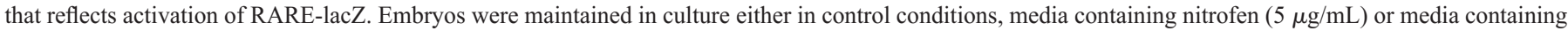

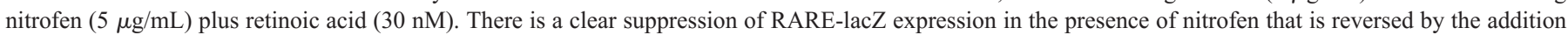
of retinoic acid to the culture medium.
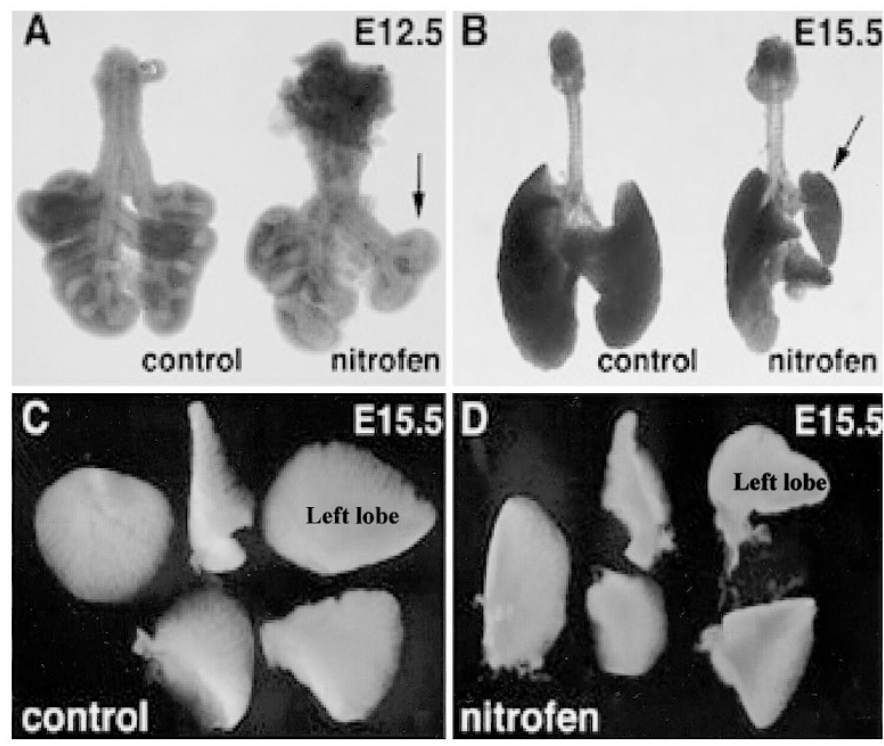

Figure 3. Photographs of embryonic lungs excised from control and nitrofen treated mice at E12.5 and E15.5. Nitrofen impairs lung morphogenesis as early as E12.5 $(A)$. Nitrofen-induced lung hypoplasia becomes more evident over time $(B)$. Although the effect of nitrofen is predominant on the left lung, lung growth is also impaired in the contralateral lung as evidenced after dissection of the right lobes $(C$ and $D)$.

\section{RELEVANCE TO CDH IN INFANTS}

The retinoid pathway is clearly complex. A disruption or an inappropriate spatiotemporal development of any one of the multiple steps could account for the defects. Transient deficiencies due to acute dietary inadequacies, impaired placental transport, spontaneous malregulation of a component of the retinoid metabolic cascade or teratogenic-mediated insults could interfere with the formation of the primordial diaphragm ( 4-5 wk gestation). Alternatively, imbalances in the levels of retinoid metabolites, binding proteins, nuclear receptors or retinoid metabolizing enzymes, regardless of retinoid levels, would lead to abnormal retinoid signaling.

To date, the only clinical data linking $\mathrm{CDH}$ and retinoids arises from a study in which markers of vitamin A status (i.e. retinol and retinol-binding-protein plasma levels) were found to be decreased by $\sim 50 \%$ in a small number of newborns with $\mathrm{CDH}$ compared with healthy newborns (44). These are potentially very important preliminary observations that should be substantiated with studies from a larger population base.

Chromosomal defects account for $\sim 10 \%$ of $\mathrm{CDH}$ cases. Enns et al. provide a comprehensive summary of congenital diaphragmatic defects and associated syndromes, malformations and chromosome anomalies (45). Included, is an association of $\mathrm{CDH}$ with chromosome $15 \mathrm{q}$ defects. A search of available databases found that a gene on chromosome 15 in the region of the deletion or translocation (15q24-26) encodes for cellular retinoic acid binding protein-1 (CRABP1). As the genome becomes better characterized, it will be interesting to examine the defective chromosomal regions for further evidence of genes that modulate or are directly involved with the retinoid-signaling pathway.

\section{CONCLUSION}

In summary, a foundation and direction for research into the etiology of $\mathrm{CDH}$ has been lacking. Given the substantial mortality and morbidity associated with this not so uncommon developmental anomaly advancements in this area will be critical. Retinoids play a central role in many biologic processes in general (46) and during embryogenesis and lung development in particular (47-49). We feel that there is now sufficient circumstantial and direct experimental evidence to warrant further testing of the retinoid-CDH etiology hypothesis. This should include examination of gene targets regulated by retinoid signaling that could be candidates for involvement in the etiology of $\mathrm{CDH}$.

\section{REFERENCES}

1. Jacobs P, Finer NN, Robertson CM, Etches P, Hall EM, Saunders LD 2000 A cost-effectiveness analysis of the application of nitric oxide versus oxygen gas for near-term newborns with respiratory failure: results from a Canadian randomized clinical trial. Crit Care Med 28:872-878

2. Thebaud B, Mercier JC, Dinh-Xuan AT 1998 Congenital diaphragmatic hernia. A cause of persistent pulmonary hypertension of the newborn which lacks an effective therapy. Biol Neonate 74:323-336

3. Bohn D 2002 Congenital diaphragmatic hernia. Am J Respir Crit Care Med 166:911915 
4. Nobuhara KK, Lund DP, Mitchell J, Kharasch V, Wilson JM 1996 Long-term outlook for survivors of congenital diaphragmatic hernia. Clin Perinatol 23:873-887

5. Langham MR, Jr, Kays DW, Ledbetter DJ, Frentzen B, Sanford LL, Richards DS 1996 Congenital diaphragmatic hernia. Epidemiology and outcome. Clin Perinatol 23:671-688

6. 1997 Inhaled nitric oxide and hypoxic respiratory failure in infants with congenital diaphragmatic hernia. The Neonatal Inhaled Nitric Oxide Study Group (NINOS). Pediatrics 99:838-845

7. Metkus AP, Esserman L, Sola A, Harrison MR, Adzick NS 1995 Cost per anomaly: what does a diaphragmatic hernia cost? J Pediatr Surg 30:226-230

8. Sokol J, Bohn D, Lacro RV, Ryan G, Stephens D, Rabinovitch M, Smallhorn J, Hornberger LK 2002 Fetal pulmonary artery diameters and their association with lung hypoplasia and postnatal outcome in congenital diaphragmatic hernia. Am J Obstet Gynecol 186:1085-1090

9. Ambrose AM, Larson PS, Borzelleca JF, Smith RB, Jr., Hennigar GR, Jr 1971 Toxicologic studies on 2,4-dichlorophenyl-p-nitrophenyl ether. Toxicol Appl Pharmacol 19:263-275

10. Costlow RD, Manson JM 1981 The heart and diaphragm: target organs in the neonatal death induced by nitrofen (2,4-dichlorophenyl-p-nitrophenyl ether). Toxicology 20:209-227

11. Kluth D, Kangah R, Reich P, Tenbrinck R, Tibboel D, Lambrecht W 1990 Nitrofeninduced diaphragmatic hernias in rats: an animal model. J Pediatr Surg 25:850-854

12. Migliazza L, Xia H, Diez-Pardo JA, Tovar JA 1999 Skeletal malformations associated with congenital diaphragmatic hernia: experimental and human studies. J Pediatr Surg 34:1624-1629

13. Mey J, Babiuk RP, Clugston R, Greer JJ 2003 Retinal dehydrogenase-2 is inhibited by compounds that induce congenital diaphragmatic hernias in rodents. Am J Patho 162:673-679

14. Wilcox DT, Irish MS, Holm BA, Glick PL 1996 Animal models in congenital diaphragmatic hernia. Clin Perinatol 23:813-822

15. Greer JJ, Allan DW, Babiuk RP, Lemke RP 2000 Recent advances in understanding the pathogenesis of nitrofen-induced congenital diaphragmatic hernia. Pediatr Pulmonol 29:394-399

16. Kluth D, Losty PD, Schnitzer JJ, Lambrecht W, Donahoe PK 1996 Toward understanding the developmental anatomy of congenital diaphragmatic hernia. Clin Perinatol 23:655-669

17. Allan DW, Greer JJ 1997 Pathogenesis of nitrofen-induced congenital diaphragmatic hernia in fetal rats. J Appl Physiol 83:338-347

18. Greer JJ, Cote D, Allan DW, Zhang W, Babiuk RP, Ly L, Lemke RP, Bagnall K 2000 Structure of the primordial diaphragm and defects associated with nitrofen-induced CDH. J Appl Physiol 89:2123-2129

19. Babiuk RP, Zhang W, Clugston R, Allan DW, Greer JJ 2003 Embryological origins and development of the rat diaphragm. J Comp Neurol 455:477-487

20. Babiuk RP, Greer JJ 2002 Diaphragm defects occur in a CDH hernia model independently of myogenesis and lung formation. Am J Physiol Lung Cell Mo Physiol 283:L1310-1314

21. Thebaud B, de Lagausie P, Forgues D, Aigrain Y, Mercier JC, Dinh-Xuan AT 2000 ET(A)-receptor blockade and ET(B)-receptor stimulation in experimental congenital diaphragmatic hernia. Am J Physiol Lung Cell Mol Physiol 278:L923-932

22. Jesudason EC, Connell MG, Fernig DG, Lloyd DA, Losty PD 2000 Early lung malformations in congenital diaphragmatic hernia. J Pediatr Surg 35:124-127; discussion 128

23. Keijzer R, Liu J, Deimling J, Tibboel D, Post M 2000 Dual-hit hypothesis explain pulmonary hypoplasia in the nitrofen model of congenital diaphragmatic hernia. Am J Pathol 156:1299-1306

24. Acosta JM, Thebaud B, Castillo C, Mailleux A, Tefft D, Wuenschell C, Anderson KD, Bourbon J, Thiery JP, Bellusci S, Warburton D 2001 Novel mechanisms in murine nitrofen-induced pulmonary hypoplasia: FGF- 10 rescue in culture. Am J Physiol Lung Cell Mol Physiol 281:L250-257

25. Guilbert TW, Gebb SA, Shannon JM 2000 Lung hypoplasia in the nitrofen model of congenital diaphragmatic hernia occurs early in development. Am J Physiol Lung Cell Mol Physiol 279:L1159-1171
26. Iritani I 1984 Experimental study on embryogenesis of congenital diaphragmatic hernia. Anat Embryol 169:133-139

27. Anderson DH 1941 Incidence of congenital diaphragmatic hernia in the young of rats bred on a diet deficient in vitamin. Am J Dis Child 62:888-889

28. Anderson DH 1949 Effect of diet during pregnancy upon the incidence of congenital hereditary diaphragmatic hernia in the rat. Am J Path 25:163-185

29. Wilson JG, Roth CB, Warkany J 1953 An analysis of the syndrome of malformations induced by maternal vitamin A deficiency. Effects of restoration of vitamin A at various times during gestation. Am J Anat 92:189-217

30. Warkany JRC, Wilson JG 1948 Multiple congenital malformations: a consideration of etiologic factors. Pediatrics 1:462-471

31. Bavik C, Ward SJ, Ong DE 1997 Identification of a mechanism to localize generation of retinoic acid in rat embryos. Mech Dev 69:155-167

32. Mendelsohn C, Lohnes D, Decimo D, Lufkin T, LeMeur M, Chambon P, Mark M 1994 Function of the retinoic acid receptors (RARs) during development (II). Multiple abnormalities at various stages of organogenesis in RAR double mutants. Development 120:2749-2771

33. Lohnes D, Mark M, Mendelsohn C, Dolle P, Decimo D, LeMeur M, Dierich A, Gorry P, Chambon P 1995 Developmental roles of the retinoic acid receptors. J Steroid Biochem Mol Biol 53:475-486

34. Chen M, MacGowan A, Ward S, Bavik C, Greer JJ 2003 Activation of the retinoid response element is inhibited in an animal model of congenital diaphragmatic hernia. Biol Neonate 83:157-161

35. Malpel S, Mendelsohn C, Cardoso WV 2000 Regulation of retinoic acid signaling during lung morphogenesis. Development 127:3057-3067

36. Thebaud B, Tibboel D, Rambaud C, Mercier JC, Bourbon JR, Dinh-Xuan AT, Archer SL 1999 Vitamin A decreases the incidence and severity of nitrofen-induced congenital diaphragmatic hernia in rats. Am J Physiol 277:L423-429

37. Thebaud B, Barlier-Mur AM, Chailley-Heu B, Henrion-Caude A, Tibboel D, DinhXuan AT, Bourbon JR 2001 Restoring effects of vitamin A on surfactant synthesis in nitrofen- induced congenital diaphragmatic hernia in rats. Am J Respir Crit Care Med 164:1083-1089

38. Fauza DO, Wilson JM 1994 Congenital diaphragmatic hernia and associated anomalies: their incidence, identification, and impact on prognosis. J Pediatr Surg 29:11131117

39. Losty PD, Vanamo K, Rintala RJ, Donahoe PK, Schnitzer JJ, Lloyd DA 1998 Congenital diaphragmatic hernia- does the side of the defect influence the incidence of associated malformations? J Pediatr Surg 33:507-510

40. Takahashi YI, Smith JE, Goodman DS 1977 Vitamin A and retinol-binding protein metabolism during fetal development in the rat. Am J Physiol 233:E263-272

41. Acosta JM, Chai Y, Meara JG, Bringas P, Jr., Anderson KD, Warburton D 2001 Prenatal exposure to nitrofen induces Fryns phenotype in mice. Ann Plast Surg 46:635-640

42. Cilley RE, Zgleszewski SE, Krummel TM, Chinoy MR 1997 Nitrofen dosedependent gestational day-specific murine lung hypoplasia and left-sided diaphragmatic hernia. Am J Physiol 272:L362-371

43. Wickman DS, Siebert JR, Benjamin DR 1993 Nitrofen-induced congenital diaphragmatic defects in CD1 mice. Teratology 47:119-125

44. Major D, Cadenas M, Fournier L, Leclerc S, Lefebvre M, Cloutier R 1998 Retinol status of newborn infants with congenital diaphragmatic hernia. Pediatr Surg Int 13:547-549

45. Enns GM, Cox VA, Goldstein RB, Gibbs DL, Harrison MR, Golabi M 1998 Congenital diaphragmatic defects and associated syndromes, malformations, and chromosome anomalies: a retrospective study of 60 patients and literature review. Am J Med Genet 79:215-225

46. McGowan SE 2002 Contributions of retinoids to the generation and repair of the pulmonary alveolus. Chest 121:206S-208S

47. Morriss-Kay GM, Sokolova N 1996 Embryonic development and pattern formation. FASEB J 10:961-968

48. Massaro GD, Massaro D 1997 Retinoic acid treatment abrogates elastase-induced pulmonary emphysema in rats. Nat Med 3:675-677

49. Chytil F 1996 Retinoids in lung development. FASEB J 10:986-992 